\title{
Conservation of Electricity Using Programmed Smart Street Lights
}

\author{
Suraj B S ${ }^{1 *}$, Chaitrashree $\mathrm{R}^{2}$, Abhishek $\mathrm{J}^{1}$, Raghavendra S. Maiya ${ }^{1}$ \\ ${ }^{1}$ Department of Computer Science \& Engineering, P.E.S College of Engineering, Mandya \\ ${ }^{2}$ Department of Information Science \& Engineering, MIT, Mysore
}

DOI: https://doi.org/10.21467/proceedings.1.72

* Corresponding author email: suraj.pesce@gmail.com

\begin{abstract}
Smart street lights system includes the automation of street lights to decrease the manpower required to maintain it. The main reason for automating street lights is to stop street lights from consuming maximum electricity when there are no vehicles or pedestrians are moving on streets. The Smart street light will be switched to glow brighter when there are vehicles on the street or pedestrians are walking on park otherwise the lights will be turned to glow dim. With advancement of innovation, things are getting to be less complex and less demanding for everybody on the world today. Automation can be characterized as innovation by which a procedure or system is performed without human help. Automation assumes an undeniably vital part on the world economy and in day by day encounter. Along with this we also can to generate $45 \%$ more electricity by building a system which consists of solar panel that tracks the position of sun and absorbs more light.
\end{abstract}

Keywords: LDR, LED, PWM.

\section{INTRODUCTION}

Automation plays an increasingly important role in the world economy and in daily life. Automatic systems are relatively more beneficial when compared to manual systems. The research work shows automatic control of streetlights as a result of which power is saved to some extent. Basically, street lighting is considered as one of the important aspect. Therefore, the street lamps are relatively simple but as a result of urbanization, the number of streets with high traffic density is rapidly increasing. At the beginning, street lamps were controlled manually where a control switch is set in each of the street lamps these are the first generation of the original street light. After that, another method that has been implemented was the optical control method: done using high pressure sodium lamp in their system. The classification of the road light system can be done based on the type of lamps used such as incandescent, mercury vapor, metal halide, high pressure sodium light, low pressure sodium light, fluorescent light, compact fluorescent light, induction light and LED (Light Emitting Diode) light. Different method of light technology used in lighting design with their lamp service life, luminous efficiency and their considerations such as performance and installation

(C) 2018 Copyright held by the author(s). Published by AIJR Publisher in Proceedings of the $3^{\text {rd }}$ National Conference on Image Processing, Computing, Communication, Networking and Data Analytics (NCICCNDA 2018), April 28, 2018.

This is an open access article under Creative Commons Attribution-NonCommercial 4.0 International (CC BY-NC 4.0)

license, which permits any non-commercial use, distribution, adaptation, and reproduction in any medium, as long as the original work is properly cited. ISBN: 978-81-936820-0-5 
area. The LED is considered as a solution to modern street lights due to its advantages and behavior. Thus, the research work highlights the energy efficient system of the street lights system using LED lamps with LDR (Light Dependent Resistors) interface for managing and controlling. These LDR's can be used to make street light to glow brighter by sensing the headlight of vehicles and then return to its normal brightness. Sun tracking solar system can be built by making use of LDR which helps the solar panel to rotate towards a position where the panel must experience more light.

\section{CHARACTERISTICS OF THE SYSTEM}

The street lights and solar panel can be controlled automatically by using the Arduino. Arduino Uno microcontroller that interface between the LDR's and the LED's. Arduino Nano is a microcontroller that provides interface between the servo motors and the LDR's.

Characteristics of the system as follows:

Arduino Uno: Used for automating the street lights. It provides the interface between the street light and the light dependent resistor. These light dependent resistors are connected to the peripherals of the Arduino Uno. This is chosen because it is easy to manipulate the analog voltage (Pulse Width Modulation) supplied to the LED.

Arduino Nano: Used to construct the sun tracking solar panel. It provides the interface between the servo motor and the light dependent resistor. These light dependent resistorsare connected to the peripherals of the Arduino Nano. Using this, the solar panel can be made to rotate with the sun.

\section{HARDWARE DESIGN}

Hardware design refers to identification of individual components and their interrelationship. Whereas Software design is the process of implementing software solutions to problems. The important part of software design is the software requirement analysis. The details of software \&hardware design are as follows.

A. Hardware Design

Arduino board is used as the major part of the hardware. Every components of the system is connected to the Arduino board in order to interface each other.

Arduino: Readings from LDR's are frequently checked by the Arduino Uno for monitoring the LED street lights. To control Servo motor value of the LDR are read by the Arduino Nano. Both of these work under ATmega328.

LDR's: Also known as the photoresistor, a light controlled variable resistor. The resistance of light dependent resistor gets down as the incident light on the photoresistor increases. This principle can be used to make street light to glow brighter by sensing the head light of vehicles and then return to its normal brightness.

Proceedings of the $3^{\text {rd }}$ National Conference on Image Processing, Computing, Communication, Networking and Data Analytics (NCICCNDA 2018) 


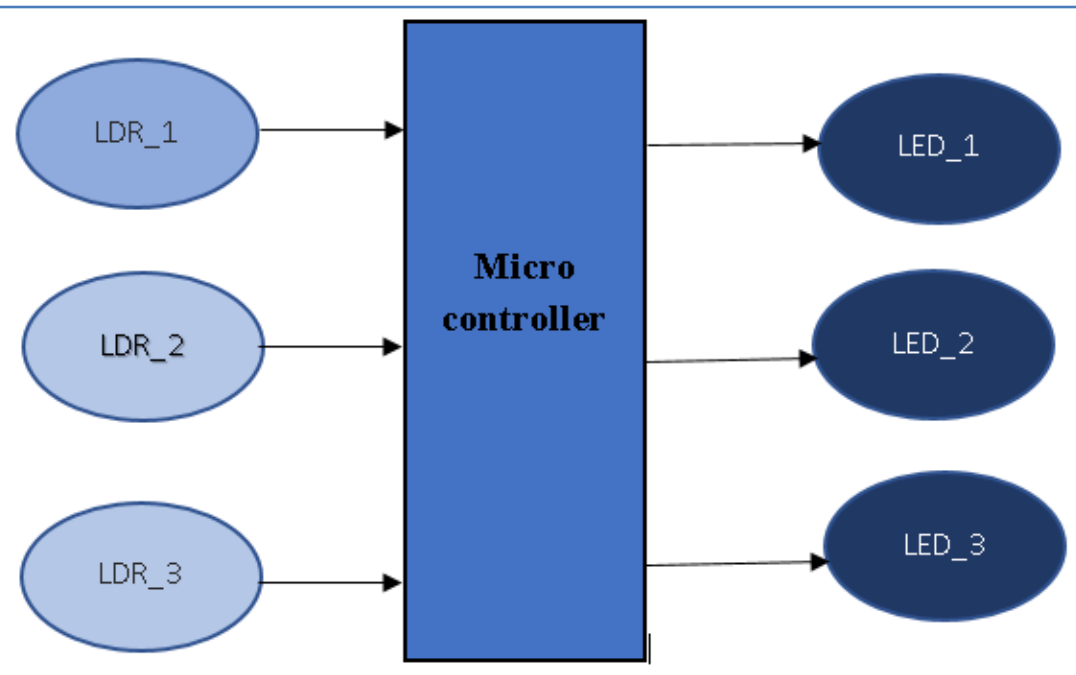

Servo Motors: This gets a control signal that represents a desired output position of the servo shaft and give power to its shaft turns to that position. This principle along with the resistance value can be used to make solar panel to rotate towards the light.

Solar panel: This consists of the solar cells. Solar panel can be used to charge the battery of 6v.

Battery: This is the power supply of 6v. This is used to power the Arduino which is connected to the LED street lights.

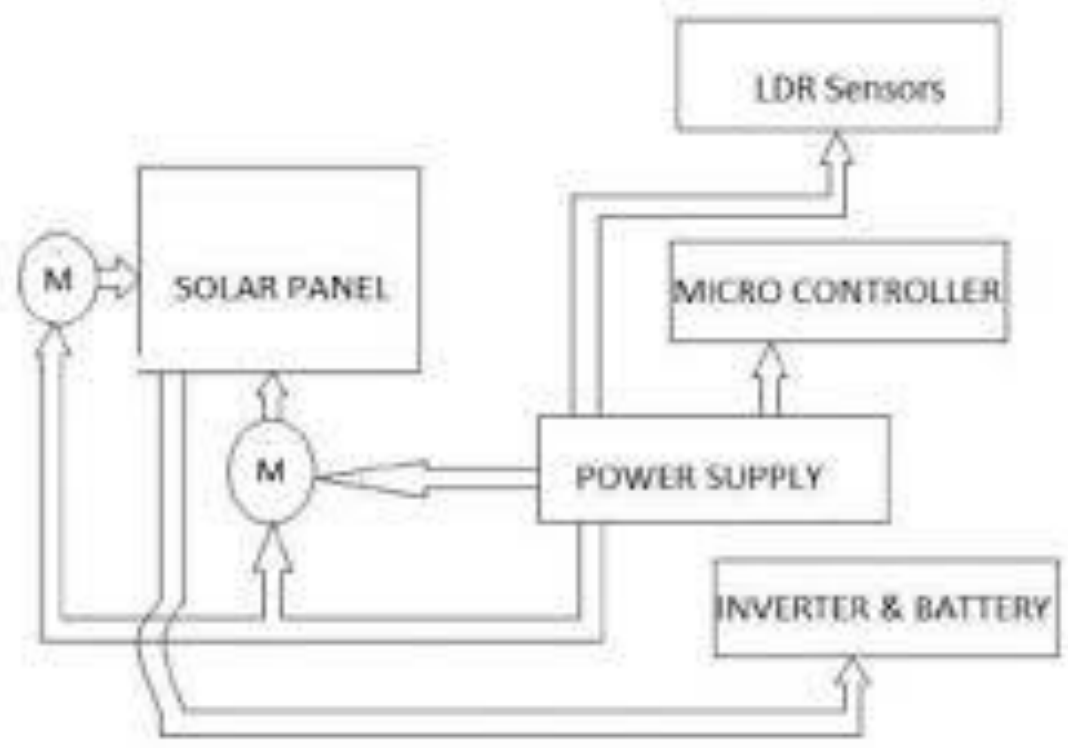

\section{EXPERIMENTAL RESULTS AND CONCLUSIONS}

The implementation of automated street lights using the LDR's allow us to build a cost effective and most efficient system that makes street light to glow brighter only when the LDR 
senses the light of the headlight of the car. In addition to this we are generating electricity in an unusual manner which allows us to increase the production by $45-50 \%$.It is reasonable to find a way to save electricity since all crude oil is getting depleted day by day so, electricity will be most important from of energy hence, this system will play most important role in production and conservation of energy.

\section{B. Software design}

\section{Working of system:}

Arduino Uno keeps track of all LDR's attached to it. Each LED in this system is associated with certain LDR. When the value read by Arduino through LDR crosses 50, the LED glows in its maximum brightness. After $30 \mathrm{sec}$ it returns to its normal brightness. Solar panel consists of 4 LDR's with the average of two LDR's at once one servo out of two can be made use to rotate the panel in vertical manner and another is used to rotate it in horizontal manner.

\section{REFERENCES}

[1].http://opensourceecology.org/wiki/Automation

[2]. S. Suganya, R. Sinduja, T. Sowmiya\& S. Senthilkumar, Street light glow on detecting vehicle movement using sensor

[3]. K.SanthaSheela,S.Padmadevi, Survey on Street Lighting System Based On Vehicle Movements

[4]. Srikanth M, Sudhakar K N,ZigBee Based Remote Control Automatic Street Light System

[5]. M.Abhishek, Syed ajram shah, K.Chetan, K,Arun Kumar, Design and implementation of traffic flow based street light control system with effective utilization of solar energy, International journal of Science Engineering and Advance Technology, IJSEAT, Vol 3, Issue 9, September -2015

[6]. C.Bhuvaneshwari, R.Rajeswari, C.Kalaiarasan, Analysis of Solar energy based street light with auto tracking system, International Journal of Advanced Research in Electrical, Electronics and Instrumentation Engineering, Vol 2, Issue 7, July 2013

[7]. Steve Chadwick, "Street Light Monitoring - a Practical Solution magazine" November/December 2002

[8]. "Intelligent Street Lighting System Using Gsm” International Journal of Engineering Science Invention ISSN (Online): 2319 - 6734, ISSN (Print): 2319 - 6726Volume 2 Issue 3 March. 2016

[9]. "Wireless internet lighting control system",Budike, E.S. Lothar (Power web Technologies), US patent 7,167,777, Jan 23, 2007.

[10]. https://en.wikipedia.org/wiki/High-intensity_discharge_lamp

[11]. http://www.hobbytronics.co.uk/arduino-uno-r3 